\title{
BMJ Open A qualitative study of pregnancy-related anxiety among women in Tanzania
}

\author{
Melanie King Rosario, ${ }^{1}$ Shahirose Sadrudin Premji, ${ }^{1,2}$ Elias Charles Nyanza,,${ }^{2,3}$ \\ Shelley Raffin Bouchal, ${ }^{1}$ David Este ${ }^{4}$
}

To cite: Rosario MK, Premji SS, Nyanza EC, et al. A qualitative study of pregnancy-related anxiety among women in Tanzania. BMJ Open 2017;7:e016072. doi:10.1136/ bmjopen-2017-016072

- Prepublication history and additional material are available. To view these files, please visit the journal online (http://dx.doi. org/10.1136/bmjopen-2017016072).

MKR and SSP contributed equally.

Received 25 January 2017 Revised 31 May 2017 Accepted 22 June 2017

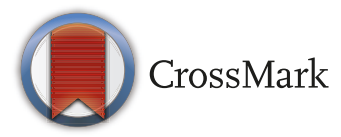

${ }^{1}$ Faculty of Nursing, University of Calgary, Calgary, Canada

${ }^{2}$ Community Health Sciences, Cumming School of Medicine, University of Calgary, Calgary,

Canada

${ }^{3}$ School of Public Health, Catholic University of Health and Allied Sciences, Mwanza, Tanzania

${ }^{4}$ Faculty of Social Work, University of Calgary, Calgary, Canada

Correspondence to Dr Shahirose Sadrudin Premji; premjis@ucalgary.ca

\section{ABSTRACT}

Objectives To explore and understand the experiences and priorities of pregnant women living with fears and worries related to fetal/infant and maternal health, the birthing process and ability to parent the infant (ie, pregnancy-related anxiety (PRA)) in Mwanza, Tanzania. Design Descriptive phenomenological approach. Setting Two clinics in the llemela and Nyamagana districts of Mwanza.

Participants Pregnant and postpartum women who obtained high scores on a PRA scale during pregnancy in a larger quantitative study were contacted to participate in an interview (10 women, aged 18-34 years; 3 HIV positive).

Measures Semi-structured interviews were undertaken, with guiding questions related to the women's experience during pregnancy. The Colaizzi method was used with transcripts that had been translated and back translated from Swahili to English and then hand-coded by the interviewer, with independent review by another researcher to verify the analysis.

Results PRA, as experienced by women in Mwanza, was a state of worry and concern, often causing physical symptoms, and disrupting personal sense of peace. While some themes in the women's experiences reflected the domains examined in the PRA scale used to identify potential participants, others such as lack of knowledge, partner relationship, interactions with the healthcare system, spirituality and fear of HIV/AIDS were otherwise missing. Their prominence in the participants' stories broadens our understanding of PRA.

Conclusions The realities and viewpoints of women in low-income and middle-income countries (LMIC) experiencing PRA are still relatively unknown. The findings from this study provided much-needed insight into the perspectives and priorities of women in Mwanza who have experienced PRA and further support the need to explore this phenomenon in other LMIC. The additional domains identified reinforce the need for a PRA tool that accurately and adequately capture the complexities of PRA for women in this region.

\section{INTRODUCTION}

Pregnancy-related anxiety (PRA) has been strongly linked to preterm births, pregnancy complications and negative infant outcomes in research from many high-income countries. ${ }^{1-9}$ PRA is a syndrome that is distinct from depression, stress or generalised
Strengths and limitations of this study

- Partnerships with the local university in Mwanza allowed involvement and collaboration with local health professionals in the development of the method, recruitment and data collection processes.

- Extensive international clinical and research experience by the researcher and supervisor was instrumental in creating relationships and opportunities for genuine interaction and conversation to ensure that the data collection and analysis process incorporated the voice of the women, local context and culture.

- This is the first qualitative study of the experiences of women who have experienced pregnancy-related anxiety in Tanzania.

- The exclusion criterion was amended to include early postpartum women as many women from the associated quantitative study began to deliver before recruitment had been completed. While we acknowledge this alteration in the study design as a potentially significant limitation, postpartum women demonstrated the ability to draw from their experience during pregnancy and their stories were rich with detail.

- The stigma of mental illness and presence of a local third party (translator) may have affected the level of participation, engagement or willingness of women to participate in the interviews.

Due to time constraints, it was not feasible to return to the participants to present initial findings and collect feedback, as per Colaizzi's method.

anxiety. ${ }^{10}{ }^{11}$ PRA encompasses several dimensions including fears and worries about the health and survival of the unborn child, having an 'abnormal' baby, the birthing process, developing medical problems during pregnancy and ability to parent and care for the infant following birth. ${ }^{10-16}$ In low-income and middle-income countries (LMIC), the presence and impact of PRA will be even more pronounced given the high maternal and child mortality rates, poverty and lack of resources.

In 2012, women in LMIC had a 1 in 150 risk of dying from complications in childbirth or pregnancy; this was in sharp contrast to a risk 
of 1 in 3800 for women in high-income countries. ${ }^{17}$ In 2012, Canada reported 555 infants deaths due to complications from preterm birth, which is the greatest cause of neonatal deaths globally, whereas Tanzania reported over $17000 .^{18}$

Despite the potential harm of PRA in women from LMIC, their realities and viewpoints are relatively unknown, as qualitative studies to date have explored the broad phenomenon of antenatal mental distress in Ethiopia, ${ }^{19}$ and Malawi, ${ }^{20}$ rather than the more specific focus of PRA. Other qualitative studies such as a study from Ghana ${ }^{21}$ have examined anxiety and fears situated in sociocultural beliefs, perceptions and knowledge, which provide insight into the affective responses of pregnant women who are anxious. ${ }^{11}$ The essence of PRA as experienced in the reality of pregnant women in LMIC is overshadowed by more widely recognised mental health concerns such as postpartum depression.

Attempts to transfer evidence from high-income countries to inform programmes or initiative in LMIC, without alterations for cultural and contextual relevancy, have often proven to be unsuccessful, if not problematic. ${ }^{22}$ In an effort to address the lack of knowledge about PRA in LMIC, this study explored the concept of PRA through the lived experience of pregnant women living in Mwanza, Tanzania. A Husserlian lens of phenomenology was integral in exploring the essence of PRA from the life-world of the participants rather than the imposition of the researcher. ${ }^{23}$ Merging the researcher's perspectives with that of the participants' lived experienced, that is applying Heideggerian lens of phenomenology, was problematic and counterproductive given the unique geographical, cultural and contextual elements within the participant's experiences and environment. ${ }^{24}{ }^{25} \mathrm{We}$ present major themes in the participants' stories that did not reflect the domains of the PRA scale as it reflects the range of anxiety symptoms experienced by pregnant women in LMIC. We incorporate culture and context to understand the meaning given by the participants to the PRA experiences that have taken place.

\section{METHODS}

Women's experience of PRA was explored through the Husserlian lens of descriptive phenomenology ${ }^{23-25}$ rather than a Heideggerian interpretive approach. ${ }^{23}$ A reflective journal, commenced prior to starting the study and maintained throughout the study process, enabled the researcher (MKR) to recognise and set aside presuppositions, judgements, beliefs, experiences and perceptions. ${ }^{26}$ As such, bracketing permitted reducing the experience to the essence of PRA as experienced by women in Mwanza, free from conscious interpretation and researchers' influence. ${ }^{23-25}$ Important elements of the participants' experiences-gender-related inequities, low literacy, low education and lack of decision-making authority-were clarified through field notes and peer debriefing. ${ }^{25} 27$ Peer debriefing, which occurred at the conclusion of each interview, enabled verification of local cultural nuances by 'cultural insiders', thereby minimising personal or cultural bias. ${ }^{28}$ To further enhance credibility, we acknowledged the community-employees and students at the Catholic University of Health and Allied Sciences office, local personnel (eg, shopkeepers, taxi drivers and neighbours) - as arbitrators of quality in discussing elements of local context and their meaning, as well as returning to raw data. ${ }^{28}$

\section{Setting and participants}

The study sample was obtained from a quantitative study underway to examine the individual and collective contribution of PRA and depression in the prediction of preterm birth and postpartum depression. ${ }^{29}$ The quantitative study recruited pregnant women from antenatal clinics in the Ilemela and Nyamagana districts of Mwanza, Tanzania. The clinic provided care to 40-50 women daily; $40 \%$ of these women deliver at hospitals and health centres that provide maternal and child health and delivery facilities. ${ }^{29}$

Purposive sampling was employed to identify women (a) 18-34 weeks' gestation, (b) able to speak English or Swahili and (c) with high scores on the 10-item PRA scale, ${ }^{14}$ which assesses fetal health, loss of fetus, childbirth, mother's well-being, parenting and control/ confidence. ${ }^{11} 14$ Eligible scores from the PRA with 4-point Likert scale were determined using the recommendations of three or more responses indicating high anxiety by Fairlier $e t a l .{ }^{30}$ As research staff reviewed records of women enrolled in the quantitative study, they identified and contacted eligible participants. The potential pool of participants was smaller than anticipated, as contacting women after they had left the clinic proved challenging and women began to deliver. Through a consultative process with the research team of the quantitative study, and approved by ethics, the sample included pregnant and postpartum women with (1) three or more responses indicating high anxiety, (2) two high anxiety and at least two moderate anxiety responses or (3) one high anxiety and at least three moderate anxiety responses. Recruitment was ongoing as interviews took place; repetition of discovered information and confirmation of data that had been previously collected was achieved after 10 interviews, indicating data saturation. ${ }^{31}$

\section{Data collection}

A research associate inquired via direct telephone interaction, using a standard script in Swahili, about women's interest to participate in an interview in a private room at a familiar antenatal clinic. During the face-to-face contact, details about the study including purpose of study, time commitment, risks, benefits, privacy, consent and voluntary nature of participation were shared prior to obtaining informed consent. A trained interviewer (MKR) conducted semi-structured interviews in the clinics in Mwanza from October to November of 2014. The interview guide (see online supplementary appendix A) provided general questions to direct participants in a 
uniform manner; interviews were also participant directed and the interviewer took cues, probed and requested further detail based on the information that was shared. Interviews were 40-75 min long, and were (a) conducted with the help of a Swahili translator, (b) audio-recorded with permission, (c) transcribed in Swahili and (d) translated to English and back-translated to Swahili to ensure language equivalency. Field notes were maintained throughout the study and used to complement the interview data and emphasise the essence of the participants' experiences of PRA. Other sources of data included demographic information about the participants, which was obtained from the larger study to reduce participant burden.

\section{Analysis}

The Colaizzi method, with the exception of the final step of validating data with the participants, guided the analytic process. ${ }^{3132}$ Each audio recording and transcript was reviewed numerous times while reflecting on field observations (eg, facial expressions, gestures, disposition). ${ }^{31}$ Bracketing continued during this process to set aside beliefs, preconceptions and values and be fully immersed in the participants' descriptions. Significant statements and phrases that pertained to PRA were identified, extracted, compiled into a separate document, reviewed and associated with a formulated meaning and assigned to a broad category, or theme. ${ }^{31}{ }^{32}$ A second researcher (SP) verified the process and ensured consistency in the meanings derived from statements, referring to the raw data as needed. ${ }^{33}$ Formulated meanings associated with each significant statement were organised into categories or unique structure of clusters of themes and incorporated together to create a specific thematic impression. ${ }^{31}{ }^{32}$ After merging all themes, we compiled a thematic map and an exhaustive description of the phenomenon of PRA in Mwanza, Tanzania. ${ }^{31}$ Participant names were anonymised using pseudonyms and participant numbers correlating to the quantitative study.

We examined consistency of qualitative data against the 10 items on the PRA scale. Cross-verification or triangulation of data enabled examination of the phenomenon of PRA from multiple perspectives. ${ }^{34} 35$ An additional method of triangulation, peer debriefing, prevented bias and allowed alternate points of view to emerge in the understanding of local context and culture. ${ }^{27}$ Peer debriefing occurred with the interpreter, members of the community, employees and students at the Catholic University of Health and Allied Sciences office and community members, including shop keepers, taxi drivers and neighbours. Although the PRA scale reflected participants' experience, additional domains of PRA were also identified. The prominence of these domains in the participants' stories is important in broadening the understanding of the phenomenon of PRA. We present these additional domains of PRA in the findings.

\section{Limitations}

Enrolling women in postpartum period did not overly influence their ability to recall the experience of PRA as evident from the richness of the stories. Women were encouraged to reflect only on their experience during pregnancy. Noticeably, anxiety as a mental health concern was absent in women's narratives. Colleagues and research associates in Tanzania, rather than the participants' interview, related the social negative attitudes surrounding mental illness (eg, work of evil spirits, possessed or bewitched). The stigma attributed to 'mental illness' and the presence of a translator may have affected the level of participation or engagement in the interviews. ${ }^{36}$ The inability to return to the participants to validate the study findings is also acknowledged as a limitation.

\section{RESULTS}

All of the women resided in semi-urban areas, urban areas or rural areas with reasonable access to semi-urban centres in Mwanza. Women were aged between 18 and 34 years. Of the 10 women, 4 were pregnant at the time of the interview and 6 had already delivered. Seven of the women $(70 \%)$ were multiparous, and two had previously experienced the death of a child. Most of the women $(90 \%)$ indicated that they were married or cohabitating with the child's father. Three of the women were HIV positive. Levels of education varied from no schooling to higher levels of basic education. Participants' characteristics are presented in table 1.

Five themes, presented in table 2, did not reflect domains of the PRA scale: knowledge and understanding,

\begin{tabular}{|c|c|}
\hline Characteristics & $n=10$ \\
\hline Age & 18-34 years \\
\hline \multicolumn{2}{|l|}{ Marital status } \\
\hline Single & 1 \\
\hline Married or cohabitating & 9 \\
\hline \multicolumn{2}{|l|}{ Parity } \\
\hline Primiparous & 3 \\
\hline Multiparous & 7 \\
\hline \multicolumn{2}{|l|}{ Previous loss of child } \\
\hline No & 8 \\
\hline Yes & 2 \\
\hline \multicolumn{2}{|l|}{$\begin{array}{l}\text { Pregnancy status at time of } \\
\text { interview }\end{array}$} \\
\hline Pregnant & 4 (16-36 weeks' gestation) \\
\hline Delivered & 6 \\
\hline \multicolumn{2}{|l|}{ HIV status } \\
\hline Negative & 7 \\
\hline Positive & 3 \\
\hline
\end{tabular}


Table 2 Additional domains of pregnancy-related anxiety as detailed by participant narratives in Mwanza

\begin{tabular}{|c|c|}
\hline Additional domains & Potential probes \\
\hline \multirow[t]{2}{*}{ Knowledge and understanding } & I have a lot of fear because I don't have enough information. \\
\hline & $\begin{array}{l}\text { I am concerned (worried) because the health care provider could not give me } \\
\text { information. }\end{array}$ \\
\hline \multirow[t]{2}{*}{ Partner relationship } & I am worried because my partner is not around. \\
\hline & I worry about finances because my partner does not support me financially. \\
\hline \multirow{2}{*}{$\begin{array}{l}\text { Interactions with the healthcare system } \\
\text { (including access to care and quality of } \\
\text { care) }\end{array}$} & I am concerned that I may need additional care or medication that I can't afford. \\
\hline & I am worried that health care practitioners won't know how to help me. \\
\hline \multirow[t]{2}{*}{ Spirituality } & I find relief from my worries when I pray or go to church. \\
\hline & Believing in God helps me to feel peace when I am fearful. \\
\hline
\end{tabular}

partner relationships, interactions with the healthcare system, spirituality and fear of HIV/AIDS.

\section{Knowledge and understanding}

Lack of knowledge, or understanding of what was normal, was an underlying issue in many of the worries participants had about pregnancy and taking care of a new baby. Berta disclosed:

I get frantic at times because I know that my knowledge and understanding of what a baby might be suffering from in low. Currently she is active in my belly. But when she is born, she might cry at night and there is no one to help me learn what might be wrong with her. Mostly I will guess. But for the days and nights now, I worry what could happen to her because of me.

Margaret found herself asking people around her about symptoms she was experiencing. "For instance, last week I had very severe abdominal pain for about 3 hours; I could not sleep. People tell me that it is a normal situation". Neema experienced heightened anxiety as she could not understand her somatic symptoms explaining:

I felt bad and I was ill. About my health, after seeing myself very thin since I was so often ill, though it (was) for all my pregnancies but in this one it was severe with a lot of stress... The felling of body weakness and fatigability went throughout the pregnancy.

Both Neema and Margaret experienced symptoms that they feared might be attributed to HIV and were terrified that this might be the cause of their symptoms. Margaret 'fail(ed) to eat' and was 'vomiting a lot', while Neema 'felt ill', became 'very thin' and was overcome with 'weakness', all of which contributed to the fear of having HIV. Neema explained, "I was tested when I was about 8 months pregnant for HIV infection and I was fine, I was not infected. But all those months, I thought I was". Although both were tested and received results that they were not HIV positive, their lack of knowledge of common somatic symptoms of pregnancy caused significant distress.

\section{Partner relationships}

Grace described the support her partner provided after she and their first child was diagnosed with HIV as, "(he) didn't disturb or humiliate me as for why he has no AIDS and we do, he accepted us". Grace kept on thinking of the current pregnancy "if all my children will be infected how things would be. Even when I rest for a few days, about 3 or more days then the concerns keep on coming back". Neema candidly shared the worries caused as result of her husband:

I don't know what was the issue but they say some might hate you when you are pregnant, I thought that was the reason. When you are in such situation and he comes asking for sex, it is an issue. It was very difficult for me...maybe because he found me often sick, maybe he was hurting inside...happiness diminishes, love fades away. I thought he might have been seeing another woman. I don't know, but at the late stages of my pregnancy be became close, he changed and that was a relief.

There were participants who had longed for emotional support from their partners but were unable to obtain it. Grace's husband travelled frequently; she explained "as his work is that he has to travel...he is often not at home...he does not stay at home most of the time. So it is not easy to tell him what happens to me every day". Berta explained that at one point in her pregnancy,

My partner took me to my parents' place and left me there. No one would talk to me without my husband there. Even visitors would only talk to my father. It was not like they were coming for me, or to know how 
I feel or how I was doing. They had no time to ask all that.

Conversations with research associates revealed that women in Tanzania (or Tanzanians in general) often do not discuss personal concerns with friends, or even family. Once Berta returned from her parents' place, she explained,

During that time (pregnancy) my husband was not around, he had travelled. We had poor communication when he was away. Whenever I called, he was not reachable. At the time he was away, I was already confused because (of) my situation and I needed him... but at the time I couldn't get through to him, I was very worried during that time.

For participants in this study, the notion of support was contextually and culturally defined as financial support, as gleaned from peer debriefing. Aisha had moved to Mwanza from her rural hometown, where weeks passed since her partner left. Aisha had little contact with the father of her unborn child, and received little help when he did respond. "What gave me worries was...there were times I...asked for support and he wouldn't help me". Aisha had moved to Mwanza from her rural hometown, where weeks passed since her partner left. She recalled, "During that time, when it happens that I face financial issues and I ask him for help and he (father of the child) doesn't respond, I was just... crying. What if I needed medicine?"

\section{Interactions with the healthcare system}

All participants in this study received antenatal care at least once during pregnancy. Margaret shared "I am used to calling the nurse whenever I get worse, I meet her and she helps me". Margaret would "do whatever the doctors instructed (her) to do' and found "I feel peace whenever I go to the hospital, since (she) gets advice from them to be well and keep (her) baby well". Joyce also recalled positive interactions with healthcare providers; however, "what I see is, they (health care providers) are more supportive in this pregnancy, especially the nurses. Whenever I face a problem they advise and help me". However, some women experienced less favourable interactions. Berta recalled a stressful week in which numerous providers contradicted her diagnosis of 'low blood' (a common term used to mean anaemia-often women will know this phrase in English without the need for translation) and informed her "that I might fall down or deliver a dead baby or that is how all of my reproduction will be". The worry in her voice and the expression on her face depicted even more than her words. Her voice grew shaky, her eyes began to water and she fidgeted with her hands in her lap. Berta felt as though the interaction with healthcare providers had exacerbated her worries explaining:

So she didn't give me clear information or encourage me. I felt like she was adding on my problems since when I was trying more to get information from her, she said 'There is this lady who came here with the same situation as yours'; I directed her, so let's find her, she can give reliable information. So herself as a nurse who was just advising me on my issue couldn't know where I could get help. So I feel she added on me a load in my thoughts.

Neema described a particularly difficult day in which she had arrived very early at clinic for assessing high blood pressure. Reflecting on the process of taking number to receive service she shared:

I came early and I was ill on that day. I was the fourth lady to arrive. At a time we were provided with numbers I never knew, I had gone to the toilet and there were about 99 women in queue. I missed the number. The nurse refused to give me a number saying 'you were not around, there are people who were here early, you came late and you want number'. I shed tears, I was upset and sad, I felt bad and I was ill, I went into the room where they take physical measures.

Sarah had waited a long time to become pregnant thus when the time finally came, "I wished to see my stomach grows fast. I used to check up on myself every now and then I felt like my stomach was not growing, so I felt worried...if the child was alive inside my womb". Sarah described frustration in being advised to stay on bed rest after experiencing bleeding in the first trimester. She stated,

I don't want to take the bed rest, though they advised me to, I figured out that I couldn't because I am working...I don't have much time to stay at home (considering that) I would have to take maternity leave after delivery. I was so worried, I was frustrated. That was very hard for me.

While routine prenatal care was provided free of charge in Mwanza, ${ }^{29}$ strained relationships with healthcare providers, the inability to access additional services or lost time at work, was an underlying issue in many of the narratives.

\section{Spirituality}

The women's spirituality permeated many conversations, often woven among the fears and concerns they expressed. Imara had three girls and felt worried as her sister-in-law's wanted their brother to marry another women who may be able to give birth to boys. She explained how her belief in God helped her to 'take heart' (ie, took courage) by thinking:

God is the one who provides, it is not like I am going to the market, that I choose I want this and that, no, I encouraged myself that God is the provider you can't say that I have only girls,...I believe God knows more and I don't.

Wema's 'biggest worry was death' because "I was swollen all over the body, especially my feet and it was painful all 
over...the doctor I was advice, there were no any other cause except for the pregnancy". Wema's sister-in-law died from pre-eclampsia. When asked how she managed to cope with her worries, Wema simply replied, "I only prayed to God...I just pass through; it reach a point I had to take heart, thought it was God's plans". Similarly, Berta believed that 'God is the one who knows it all...' including her own future and if she 'will deliver safely or not'. Despite her struggles, Berta 'was encouraged by being thankful to God in everything'. Sarah had experienced particular anxiety that her stomach was not growing large enough to indicate that a healthy child lay inside. For Sarah aside from her husband "Honestly, my other help was from prayers only. When I pray I get peace of mind. I stopped worrying. I believed my stomach would get larger. So as much as we talked and prayer, I felt peace".

\section{Fear of HIV/AIDS}

Fears of HIV/AIDS consumed the thoughts of the pregnant women who could not explain their somatic symptoms. Margaret explained that, "I was vomiting a lot, not eating well, it made me have poor health and I became very thin. So I was thinking, I had not tested (for HIV) and I was very worried". She described feeling scared "after seeing myself very thin, though it (was) for all my pregnancies but in this one it was severe with a lot of stress". Neema, who also saw herself feeling thin and unwell, described,

It was during my early pregnancy but the feeling of body weakness and fatigability went throughout the pregnancy, I was tested when I was about 8 months pregnant for HIV infection, I was fine, I was not infected. My worry was because I was often sick and had lost weight so much, so event that added in my thoughts.

The three HIV-positive women had relatively recent diagnoses (within the past 3 years) were preoccupied with worries about their unborn child/infant, and concerns for their child's future if they were to pass away. Grace talked about her reactions to her HIV-positive diagnoses:

I was frightened and full of worries. I passed about three days without food since I had a lot of stress and thoughts, I was sad, I was worried and I cried so much. I never expected my baby be infected or even myself; I never knew until I became pregnant again and I found out that I was HIV infected together with my oldest child.

Grace also discussed her concerns about the antiretrovirals that she began taking during her pregnancy and their impact on her unborn child. She explained,

Those drugs were bringing me different conditions (side effects). I felt like dizziness and was thinking was these drugs to protect the child who was in my womb? If they make me feel this way, and in other days, I even lack sleep, with these conditions will my child be alive? Will the drug help me? I was worried.
Joyce's initial "concern was perhaps my child would also get infected, I asked the doctors, they reassured me and I stopped worrying". However, the initial reassurance faded as she considered her own diagnosis and then explained, "Both of my parents died and relative from my husband's side know nothing...I am worrying of delivering a baby who is HIV infected and was wondering what if I die early, who would I leave my baby with?"

\section{DISCUSSION}

The PRA scale ${ }^{14}$ has been identified as an appropriate tool for examining the experience of PRA for women in high-income countries. ${ }^{11} 16$ Nonetheless, there have been claims that this tool, along with others designed to examine this phenomenon, displays relatively narrow domains that may not reflect the essence of PRA experienced by women. ${ }^{37} 38$ Our study confirmed this assertion for women in LMIC, specifically in Mwanza. Lack of knowledge, partner relationships, interactions with the healthcare system, spirituality and fear of HIV/AIDS are suggested as additional domains based on their strong presence in the narratives and themes derived from the participants' stories. Table 1 provides suggestions for associated prompts related to each of these domains based on the participants' stories. Together with the PRA scale, these prompts may assist in developing a comprehensive measurement scale that will more accurately depict the sociocultural context of life in LMIC, specifically Mwanza, and therefore more accurately assess and identify pregnant women who are experiencing PRA in this region.

The literature on $\mathrm{PRA}^{2-9}$ outlines the numerous adverse effects for both mother and baby; many of these consequences of PRA were echoed in the participants' narratives. Participants appreciated that 'thinking too much' or worrying was bad for them, as well as the baby. Partners/husband, friends, family, neighbours and care providers informed these sentiments and "advised that the more you keep on thinking, the more you risk your baby" or you "might get miscarried or bear a child with weakness...don't stress, you might worry much and lose your life or the baby's". The stories of family, neighbours and friends become increasingly valuable as a source of information due to perceived lack of knowledge of healthcare professionals or lack of trust in their advice.

In LMIC such as Mwanza, the use of the word support was complicated by poverty, as often fathers/partners may continue to provide financial resources, exacerbating a woman's dependency for survival, while providing little to no practical or emotional support. ${ }^{39}$ There is increasing evidence that mental health issues in women may be related to social circumstances, including poverty, violence and economic dependence. ${ }^{40}$ The stories of the women in this study are similar to previous studies that indicated the significance of financial supporting women's feelings of anxiety. ${ }^{41}$

Mwanza, and Tanzania in general, remains a highly patriarchal society in which women are often not given 
ownership of their decisions, including decisions regarding health and medical care. ${ }^{39}$ Research colleagues in Mwanza indicated that this might be due to any number of issues, including inability to meet sexual needs, decreased ability to provide for the home or the partner's stress about providing for another child. For many participants, these gender-based realities of life influenced family roles, interactions and emotional support mechanisms and evoked feelings of frustration, anxiety, hopelessness and resignation. Lack of perceived control over a situation can effect an individual's uncertainty and insecurity, often leading to increased anxiety. ${ }^{42}$ Nearly all of the women used spiritual-positive coping-religion, prayer or belief in a greater power or plan-to overcome distressing situations and their potential or actual negative consequences. ${ }^{43}{ }^{44}$ Spiritual-positive coping offers a framework to help individuals make sense of the bigger life questions, placing the power of a situation on a greater entity. This can have many effects, including a reduction of guilt and feelings of responsibility for a difficult or unfortunate situation. ${ }^{45}$ Spirituality may lower anxiety levels, increase feelings of security, provide additional social support and reduce worry. ${ }^{46-48}$ Few studies have examined spirituality and mental health in Africa, despite it being recognised as a significant aspect of daily life in Tanzania. ${ }^{48}$

In LMIC, financial constraints and multiple sociopolitical problems (eg, poverty and economic instability) that burden healthcare systems ${ }^{49}$ contribute to worry and uncertainty throughout pregnancy. For participants with access to care, the experience was at times disappointing due to negative events endured with healthcare providers. In Tanzania, antenatal services are widely available; however, quality of service and treatment remains an ongoing issue due to lack of trained personnel, inadequate supplies and equipment and poor implementation of antenatal guidelines. ${ }^{50} 51$

Three of the 10 participants were HIV-positive, yet HIV played a significant role in their stories and in the lives of many of the participants. Many non-HIV-positive participants expressed constant fear or anxiety about being diagnosed with HIV. Their worries did not indicate a positive diagnosis, but rather the reality of living in a highly affected area, with a heightened sense of the reality and risks of this illness. Women with HIV have higher anxiety symptoms during pregnancy due to maternal fears related to perinatal transmission of HIV. ${ }^{52}$ All three of the participants with HIV openly discussed the intense fear of their child having HIV.

\section{CONCLUSIONS}

How social processes, poverty and culture informs mental health of women during pregnancy remains unexplored. ${ }^{2}$ The social, economic and cultural realities of women residing in Mwanza were exemplified in themes of lack of knowledge, partner relationship, interactions with the healthcare system, spirituality and fear of HIV/AIDS that emerged from the narratives of women experiencing PRA. Our study provides insight in this regard and adds new knowledge about the essence of PRA experienced by women in Mwanza, Tanzania. The PRA scale appropriately explicates participants' fear, worries and concerns related to their own health and survival during pregnancy, their infants' health during pregnancy and survival as well as caregiving ability in the post partum. The PRA scale, however, narrowly reflects domains that inform our understanding of PRA of women in Mwanza, Tanzania and perhaps other LMIC.

Acknowledgements The authors are most grateful to the women who participated in this study and bravely told their stories. The collaboration and contributions of the Catholic University of Health and Allied Sciences in Mwanza are also acknowledged, as well as the research associates, assistants and translators, particularly Dr Ola Jahanpour and Miss Audrey Bernard. The authors thank Jill Norris for technical writing assistance.

Contributors MKR and SSP developed the research question, designed the study, participated in data analysis and drafted the manuscript. ECN coordinated efforts in Mwanza, including translating documents, obtaining ethics approval and coordinating local assistants. SRB and DE provided consultation from the research design through to the manuscript development. All authors have contributed to the work and approved the manuscript.

Funding The University of Calgary Research Grant (URGC) Program, SEED Grant, funded the larger quantitative study. MRK's graduate studies was supported by scholarships including Alberta Graduate Student Scholarship, Charlotte Firth Memorial Graduate Scholarship in Community Health Nursing, Education for the Future Master of Nursing Scholarship and the Queen Elizabeth II Graduate Scholarship.

Competing interests None declared.

Ethics approval University of Calgary Conjoint Health Research Ethics Board (REB13-0399: larger study; REB14-0660: this study; and REB14-0660-MOD-1: to include postpartum women) and the Catholic University of Health and Allied Sciences.

Provenance and peer review Not commissioned; externally peer reviewed.

Data sharing statement There are ethical restrictions that prohibit us from making data publicly available. We do not have permission from the participants to share all the interview data stemming from this study, especially the transcripts from the interviews. During the informed consent process, we indicated that the data would be shared in aggregate.

Open Access This is an Open Access article distributed in accordance with the Creative Commons Attribution Non Commercial (CC BY-NC 4.0) license, which permits others to distribute, remix, adapt, build upon this work non-commercially, and license their derivative works on different terms, provided the original work is properly cited and the use is non-commercial. See: http://creativecommons.org/ licenses/by-nc/4.0/

(c) Article author(s) (or their employer(s) unless otherwise stated in the text of the article) 2017. All rights reserved. No commercial use is permitted unless otherwise expressly granted.

\section{REFERENCES}

1. Azar R, Singer S. Maternal prenatal state anxiety symptoms and birth weight: A pilot study. Open Med 2012;7:747-52.

2. Dunkel Schetter C. Psychological science on pregnancy: stress processes, biopsychosocial models, and emerging research issues. Annu Rev Psychol 2011;62:531-58.

3. Dunkel Schetter C, Tanner L. Anxiety, depression and stress in pregnancy: implications for mothers, children, research, and practice. Curr Opin Psychiatry 2012;25:141-8.

4. Gurung RAR, Dunkel-Schetter C, Collins N, et al. Psychosocial Predictors of prenatal anxiety. J Soc Clin Psychol 2005;24:497-519.

5. Lobel M, Cannella DL, Graham JE, et al. Pregnancy-specific stress, prenatal health behaviors, and birth outcomes. Health Psychol 2008;27:604-15. 
6. Mancuso RA, Schetter CD, Rini CM, et al. Maternal prenatal anxiety and corticotropin-releasing hormone associated with timing of delivery. Psychosom Med 2004;66:762-9.

7. Sawyer A, Ayers S, Smith H. Pre- and postnatal psychological wellbeing in Africa: a systematic review. J Affect Disord 2010;123:17-29.

8. Orr ST, Reiter JP, Blazer DG, et al. Maternal prenatal pregnancyrelated anxiety and spontaneous preterm birth in Baltimore, Maryland. Psychosom Med 2007;69:566-70.

9. Zachariah R. Social support, life stress, and anxiety as predictors of pregnancy complications in low-income women. Res Nurs Health 2009;32:391-404.

10. Huizink AC, Mulder EJ, Robles de Medina PG, et al. Is pregnancy anxiety a distinctive syndrome? Early Hum Dev 2004;79:81-91.

11. Bayrampour H, Ali E, McNeil DA, et al. Pregnancy-related anxiety: a concept analysis. Int $J$ Nurs Stud 2016;55:115-30.

12. Côté-Arsenault $D$. The influence of perinatal loss on anxiety in multigravidas. J Obstet Gynecol Neonatal Nurs 2003;32:623-9.

13. Levin JS. The factor structure of the pregnancy anxiety scale. $J$ Health Soc Behav 1991;32:368-81.

14. Rini CK, Dunkel-Schetter C, Wadhwa PD, et al. Psychological adaptation and birth outcomes: the role of personal resources, stress, and sociocultural context in pregnancy. Health Psychol 1999;18:333-45.

15. Theut SK, Pedersen FA, Zaslow MJ, et al. Pregnancy subsequent to perinatal loss: parental anxiety and depression. J Am Acad Child Adolesc Psychiatry 1988;27:289-92.

16. Wadhwa PD, Sandman CA, Porto M, et al. The association between prenatal stress and infant birth weight and gestational age at birth: a prospective investigation. Am J Obstet Gynecol 1993;169:858-65.

17. World Health Organization. Maternal mortality fact sheet. Geneva: World Health Organization, 2014. http://www.who.int/mediacentre/ factsheets/fs348/en/ (accessed 12 Sep 2014).

18. World Health Organization. Born too soon: Thethe global action report on preterm birth. Geneva: World Health Organization, 2012. http://www.who.int/pmnch/media/news/2012/preterm_birth_report/ en/ (accessed 20 Mar2014)

19. Hanlon C, Whitley R, Wondimagegn D, et al. Between life and death: exploring the sociocultural context of antenatal mental distress in rural Ethiopia. Arch Womens Ment Health 2010;13:385-93.

20. Stewart RC, Umar E, Gleadow-Ware S, et al. Perinatal distress and depression in Malawi: an exploratory qualitative study of stressors, supports and symptoms. Arch Womens Ment Health 2015;18:177-85.

21. Dako-Gyeke P, Aikins M, Aryeetey R, et al. The influence of sociocultural interpretations of pregnancy threats on health-seeking behavior among pregnant women in urban Accra, Ghana. BMC Pregnancy Childbirth 2013;13:211.

22. Dhai A, Noble R. Ethical issues in HIV. Best Pract Res Clin Obstet Gynaecol 2005;19:255-67.

23. Converse M. Philosophy of phenomenology: how understanding aids research. Nurse Res 2012;20:28-32.

24. Dowling M. From Husserl to van Manen. A review of different phenomenological approaches. Int J Nurs Stud 2007;44:131-42.

25. Rodgers BL. Developing nursing knowledge: philosophical traditions and influences. Philadelphia, PA: Lippincott, Williams and Wilkins, 2005.

26. Hamill C. Bracketing--practical considerations in husserlian phenomenological research. Nurse Res 2010;17:16-24.

27. Morse JM. Critical analysis of strategies for determining rigor in Qualitative Inquiry. Qual Health Res 2015;25:1212-22.

28. Mullings B. Insider or outsider, both or neither: some dilemmas of interviewing in a cross-cultural setting. Geoforum 1999;30:337-50.

29. Premji SS, Nyanza EC, Riziki P. Psychosocial health of women in Mwanza City: pregnancy-related anxiety, depression, and preterm birth. Calgary, AB: University Research Grants Committee, seed Grant application.
30. Fairlie TG, Gillman MW, Rich-Edwards J. High pregnancy-related anxiety and prenatal depressive symptoms as predictors of intention to breastfeed and breastfeeding initiation. $J$ Womens Health 2009;18:945-53.

31. Streubert HJ, Carpenter DR. Qualitative research in nursing: advancing the humanistic imperative. $5^{\text {th }}$ ed. Philadelphia PA: Lippincott, Williams and Wilkins, 2011.

32. Knaack P. Phenomenological research. West J Nurs Res 1984:6:107-14

33. Loiselle CG, Profetto-McGrath J, Polit DF, et al. Canadian essentials of nursing research. $3^{\text {rd }}$ ed. Philadelphia PA: Lippincott Williams and Wilkins, 2011.

34. Mathison S. Why Triangulate? Educational Researcher 1988;17:13-17.

35. Patton MQ. Qualitative evaluation and research methods. $3^{\text {rd }}$ ed. Thousand Oaks, CA: Sage Publications, 2002.

36. Rahman A, Fisher J, Bower P, et al. Interventions for common perinatal mental disorders in women in low- and middle-income countries: a systematic review and meta-analysis. Bull World Health Organ 2013;91:593-601.

37. Brunton RJ, Dryer R, Saliba A, et al. Pregnancy anxiety: a systematic review of current scales. J Affect Disord 2015;176:24-34.

38. Somerville S, Dedman K, Hagan R, et al. The perinatal anxiety screening Scale: development and preliminary validation. Arch Womens Ment Health 2014;17:443-54.

39. Rwakarema M, Premii SS, Nyanza EC, et al. Antenatal depression is associated with pregnancy-related anxiety, partner relations, and wealth in women in Northern Tanzania: a cross-sectional study. BMC Womens Health 2015;15:68.

40. Sawyer A, Ayers S, Smith H. Pre- and postnatal psychological wellbeing in Africa: a systematic review. J Affect Disord 2010;123:17-29.

41. Esimai OA, Fatoye FO, Quiah AG, et al. Antepartum anxiety and depressive symptoms: a study of Nigerian women during the three trimesters of pregnancy. J Obstet Gynaecol 2008;28:202-3.

42. Lazarus RS. Coping theory and research: past, present, and future. Psychosom Med 1993;55:234-47.

43. Hamilton JG, Lobel M. Types, patterns, and predictors of coping with stress during pregnancy: examination of the revised prenatal coping inventory in a diverse sample. J Psychosom Obstet Gynaecol 2008;29:97-104.

44. Lazarus RS, Folkman S. Stress, appraisal, and coping. New York: Springer, 1984.

45. Tuncay T. Spirituality in coping with HIV/AIDS. HIV \& AIDS Review 2007;6:10-15.

46. Glas G. Anxiety, Anxiety Disorders, Religion and Spirituality . South Med J 2007;100:621-5.

47. Mann JR, Mannan J, Quiñones LA, et al. Religion, spirituality, social support, and perceived stress in pregnant and postpartum hispanic women. J Obstet Gynecol Neonatal Nurs 2010;39:645-57.

48. Steglitz J, Ng R, Mosha JS, et al. Divinity and distress: the impact of religion and spirituality on the mental health of HIV-positive adults in Tanzania. AIDS Behav 2012;16:2392-8.

49. Cabieses B, Bird P. Glossary of access to health care and related concepts for low- and middle-income countries (LMICs): a critical review of international literature. Int J Health Serv 2014;44:845-61.

50. Exavery A, Kanté AM, Hingora A, et al. How mistimed and unwanted pregnancies affect timing of antenatal care initiation in three districts in Tanzania. BMC Pregnancy Childbirth 2013;13:35.

51. Nyamtema AS, Bartsch-de Jong A, Urassa DP, et al. The quality of antenatal care in rural Tanzania: what is behind the number of visits? BMC Pregnancy Childbirth 2012;12:70-8.

52. Aaron E, Bonacquisti A, Geller PA, et al. Perinatal Depression and anxiety in women with and without human immunodeficiency virus infection. Womens Health Issues 2015;25:579-85. 